\title{
“REDES SOCIAIS NA EDUCAÇÃO: EU CURTO” A EXPERIÊNCIA DE CRIAÇÃO DE UMA OFICINA PARA CAPACITAÇÃO DOCENTE NO SENAC RS
}

\author{
Nelson Luis Eufrasio Junior - Senac EAD RS - nleufrasio@senacrs.com.br \\ Gabriel Magalhães Gil - Senac EAD RS - gmagalhaes@senacrs.com.br \\ Wagner Mauat da Silva - Senac EAD RS - wsilva@senacrs.com.br
}

\begin{abstract}
Resumo: Este trabalho tem como objetivo tornar público um estudo de design educacional aplicado para a criação de uma oficina temática direcionada especialmente aos docentes do Senac RS, a ser realizada na modalidade de Educação a Distância (EAD), com o uso da Internet como ferramenta mediadora do acesso e tendo como finalidade o propósito de ser uma oportunidade de formação inicial e continuada de docentes da Instituição. Com base neste, acredita-se que sua contribuição encontra-se na inspiração de ideias oriundas do Design Thinking propostas para a criação desta oficina virtual, tendo como ponto inicial a análise do contexto em que o público-alvo encontrase inserido a fim de possibilitar novas descobertas acerca do emprego de redes sociais no cenário educacional. Sendo assim, propiciando aos docentes um novo espaço de conhecimento, em que estes se sintam acolhidos e encontrem outros parceiros de atividade docente no decorrer da construção de sua aprendizagem, todos conectados a proposta de atualização pedagógica do professor.
\end{abstract}

Palavras-chave: Educação a Distância, Design Thinking, Capacitação Docente, Design Educacional.

\section{"SOCIAL NETWORKS IN EDUCATION: I LIKE IT" THE CREATION OF EXPERIENCE OF A WORKSHOP FOR TRAINING TEACHERS IN SENAC RS}

\begin{abstract}
This paper aims to make public a study of educational design applied to the creation of a thematic workshop directed especially to the teachers of Senac RS to be held in the Distance Learning (DL) mode, using the internet as an access tool and with the purpose intended to be an opportunity of initial and continuing training of the teachers of the Institution. Based on this work, it is believed that their contribution is in the inspiration of ideas coming from the Design Thinking proposals for the creation of this virtual workshop, having as starting point the analysis of the context in which the target audience is inserted in order to enable new discoveries about the use of social networks in the educational scenario. Thus, propitiating to the teachers a new area of knowledge in which they feel welcomed and find other partners of the teaching activity during the construction of their learning, being all connected to the proposal of a pedagogical update of the teacher.
\end{abstract}

Keywords: Distance Learning, Design Thinking, Teacher Training, Educational Design. 


\section{Introdução}

O termo Design Thinking, segundo Pinheiro \& Alt (2011), é utilizado para resumir o modelo de pensamento onde a condução de situações, bem como a abordagem de problemas, é fundamentada em três conceitos essenciais, que são: empatia, colaboração e experimentação. Logo, cabe aos profissionais envolvidos neste processo de resolução de problemas projetar soluções criativas que possibilitem a resolução de problemas e uma experiência significativa ao ponto de despertar ainda mais interesse naquele que a vivencia, isto é, buscar uma oportunidade de viver algo de modo pleno, satisfatório.

Mas qual é a relação educacional com o parágrafo acima? Simples. Considerando a evolução tecnológica que vivenciamos atualmente, acreditamos ser necessário despertar no docente o desejo, a vontade de utilizar diferentes recursos que atendam às múltiplas necessidades que os alunos trazem a todo o momento. E isso acontece por meio da convergência de dados, conceitos, contextos e mídias que ocorre em espaços de aprendizagem. Aqui optamos por tratar como espaços de aprendizagem todo local em que seja possível estabelecer tal relação. Neste trabalho, através da Educação a Distância (EAD), utilizaremos como espaço de aprendizagem a plataforma Moodle e suas ferramentas de apoio ao processo de construção do conhecimento.

Considerando a crescente evolução dos recursos tecnológicos, bem como o advento das redes sociais e suas potencialidades em espaços de aprendizagem, surge a necessidade de que o docente possa sentir-se confiante no uso dessas, não apenas como entretenimento, mas também como agente de mediação entre os alunos e os demais envolvidos no contexto educacional em que estiver inserido. Schlemmer (2009) destaca que trabalhar com pessoas, ajudando-as a se desenvolverem são ações que exigem determinados níveis de complexidade. Esse novo cenário educacional está presente em diversas escolas do nosso País, onde as instituições buscam envolver a comunidade estudantil na investigação de como essas tecnologias podem contribuir. No contexto do Senac RS, não poderia ser diferente. Alunos e docentes utilizam diversas redes sociais com os mais diferentes propósitos, como Twitter, Facebook, Instagram e o LinkedIn, entre outras redes que não abordarei neste trabalho.

\footnotetext{
Assim, um dos desafios enfrentados pelas atuais instituições consiste, justamente, em promover a emancipação digital e desenvolver metodologias e processos de mediação pedagógica capazes de aproveitar as possibilidades que estes novos meios disponibilizam para os processos de ensinar e de aprender (SCHLEMMER, 2011, p. 279-280).
}

No momento em que o aluno faz uso dessas redes, é necessário que o docente as compreenda, ao invés de proibir sua utilização. Foi pensando neste contexto de promoção da emancipação digital, talvez nos seja permitido chamar de alfabetização digital social do docente, que a equipe de Tecnologias Educacionais recebeu como demanda de trabalho, originária do Núcleo de Capacitações Docentes, a missão de conceber, a partir do conteúdo previamente desenvolvido por uma docente, uma oficina cujo tema é "Redes Sociais na Educação: Eu Curto". A contribuição deste trabalho encontra-se presente no relato de como a equipe envolvida neste projeto utilizou alguns conceitos do Design Thinking para desenvolver a criação, ao ponto de romper alguns paradigmas, tornando as oficinas para capacitação docente mais atrativas aos professores participantes, pois, de acordo com Pinheiro \& Alt (2011), Design Thinking é „o jeito de pensar do design“e ou mais precisamente o „projeto centrado nas pessoas 


\section{Para todo o problema deve existir uma solução}

Contextualizando, então, o Núcleo de Capacitações Educacionais entrou em contato com a coordenação do Núcleo de Tecnologias Educacionais para a abertura de uma demanda de trabalho, algo bastante comum para nossa atividade profissional. A solicitação deste departamento consistia em construir uma oficina para abordar a necessidade de trabalhar com as redes sociais na educação, se possível fazendo uma alusão ao botão „curtir" do Facebook. Um de nós, por ser o Designer Educacional envolvido neste projeto, recebeu o conteúdo teórico e a solicitação de criação via coordenação de equipe, que prontamente explicou a necessidade e o público-alvo desta capacitação docente.

Foi então que o Designer Educacional deparou-se com o seguinte dilema: como despertar no docente as mesmas sensações de utilização da rede social Facebook se no Senac RS, por razões de gerenciamento de T.I., o acesso a essa e a outras redes sociais é bloqueado? Com esse questionamento em mente, reunimo-nos, Designers e Designer Educacional envolvidos neste projeto, e conversamos sobre nossas dúvidas, que vieram a ser as mesmas. Considerando que nosso aluno se encaixa na ideia descrita por Schlemmer (2009), ao citar que os discentes da atualidade são sujeitos que elaboraram uma pluralidade de convivência com outros sujeitos, possibilitando uma "cultura da virtualidade real”, concluímos que o docente necessita ser envolvido nessa mesma cultura.

Então, entre rascunhos, ideias mirabolantes e acesso a alguns conteúdos de blogs que julgamos na ocasião serem bobagens, mas que servem para pura e simples distração (assim como inspiração), chegamos à ideia de recriar em HTML o conteúdo desta oficina, propiciando ao docente as mesmas sensações de utilização no uso da rede social Facebook.

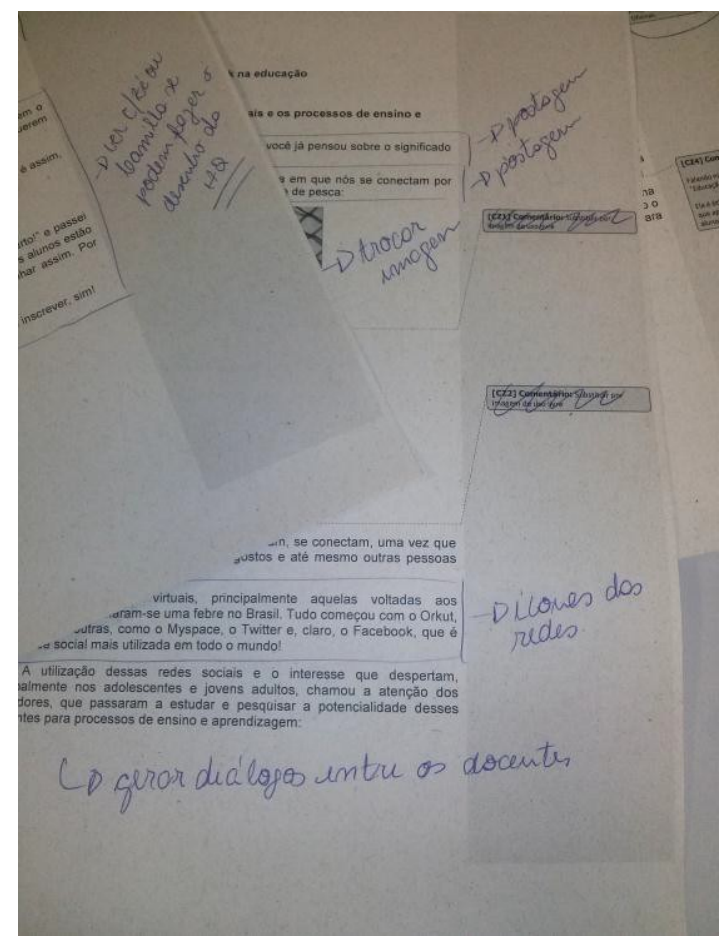

Figura 1: Rascunhos que deram origem ao resultado final (elaborado pelos autores) 
Enquanto rabiscávamos nossas ideias, nosso Designer Educacional foi convocado para uma reunião, onde deveria conversar com a coordenação da equipe de Tecnologias Educacionais e de Capacitações Docentes sobre este projeto. Neste momento, aproveitando a oportunidade que lhe foi propiciada, lançou como ideia recriarmos o ambiente do Facebook para o docente do Senac RS. Você deve se perguntar se não seria mais fácil para nós entrarmos em contato com a área de Tecnologia da Informação e solicitarmos a liberação do acesso ao Facebook. Até poderia ser, porém, ocorre que, ao abordarmos o tema „redes sociais na educação ${ }^{\text {ee }}$, não podemos resumir tudo ao Facebook simplesmente, nem podemos liberar todo e qualquer tipo de acesso em nossa rede. Era preciso ter uma boa fundamentação, saber como seria o acesso a essas redes, quais seriam as métricas do consumo de banda e quais seriam os impactos financeiros que esta liberação de rede traria para as Unidades. Ou seja, algo que, devido ao tempo para atendimento de uma demanda de trabalho corporativa, não tínhamos a nosso dispor.

Retornando à nossa reunião, foi então que o Designer Educacional apresentou os rascunhos da ideia concebida pelos envolvidos nesta etapa de criação. Note que, na imagem exibida anteriormente, não havia conceitos preestabelecidos, as ideias encontravam-se exatamente em estado bruto, aguardando para serem lapidadas. Os coordenadores ouviram atentamente os questionamentos feitos, cogitaram inclusive reuniões com a ASTI (Assessoria de Tecnologia da Informação) do Senac RS para tratar de questões referentes ao aumento da banda de internet para acesso nas escolas e unidades do Senac RS presentes no Estado, bem como do acesso a determinados sites e se possível, uma revisão nas políticas de acesso à web presentes na Instituição.

Sabíamos na ocasião que muitos fatores poderiam tornar limitado o resultado, porém resgatamos a ideia de Pinheiro \& Alt (2011) ao defenderem que “a inovação é fruto da criatividade colocada em prática com o intuito de gerar resultados positivos para o negócio e criar impacto positivo para as pessoas”. No meio corporativo, no qual estamos inseridos, em muitos casos existe um fator que limita um processo de criação, o chamado fator tempo. Neste projeto não seria diferente. Havia, como de costume, boa vontade de todas as áreas em colaborar com o êxito do projeto, porém o tempo enxuto limitava grande parte das ações.

Se em outras circunstâncias a equipe de Tecnologias Educacionais se via em completa escuridão para um problema desta amplitude, o que se viu na ocasião foi uma explosão de ideias e criatividade, tendo em vista que o desejo comum a todos nós era o de impactar, de maneira positiva, todas as pessoas envolvidas nesta capacitação docente, possibilitando resultados educacionais positivos para o Senac RS.

\footnotetext{
Nem sempre a novidade, ou a inovação surge como uma invenção, algo materializável ou manipulável. Algumas transformações do pensamento, novas ideias e ideais possuem a mesma, ou senão até maior, força transformadora que algumas invenções. O que de fato se pode apontar em relação às inovações é que a sua importância ou atribuição de valor está diretamente relacionada aos efeitos que produz ou às transformações que provoca. É assim que a novidade quase sempre surge em oposição a alguma coisa, seja da resolução de problemas, seja da resposta a uma necessidade do espírito humano (LOPES, 2010, pg. 28-29).
}

Talvez fosse a melhor solução buscar a acomodação presente em algumas situações, isto é, fazer o dito "arroz com feijão”, porém não era o que nós buscávamos. A necessidade de algo que nos desafiasse criativamente, que nos fizesse pensar e agir diante da incerteza, era o que motivava cada um a buscar o melhor de si para este projeto, para o resultado final desta criação, para o desenvolvimento deste projeto. 
Então, começaram nossas buscas por telas de referência do Facebook, Instagram, Youtube e Twitter, como exemplos de redes acessadas pelos alunos e professores do Senac RS.

Ao desenvolver o processo que chamamos de análise didática do material teórico entregue pelo docente, nos foi possível identificar os elementos essenciais para a utilização do Design Thinking como inspiração nesta criação. Segundo Eufrasio Jr. (2013) o material educacional digital permite amplas possibilidades de uso, devido aos diferentes recursos que podem ser empregados em sua construção, fato que permite ainda a sua inserção em múltiplas propostas pedagógicas, ocasionando assim o desenvolvimento de uma constante cultura digital. Em complemento a este, trazemos neste momento o seguinte recorte:

Assim, na cultura digital, a ênfase está na interação, no fluxo, na conectividade, na rede, nas novas formas de relações sociais e institucionais, na cooperação, no compartilhamento, nas múltiplas linguagens, no digitalizar. (LOPES E VALENTINI, 2012, p.207).

Seguindo a linha de raciocínio exposta anteriormente, buscamos então realizar uma distribuição de tarefas, a fim de otimizar o tempo de produção do material a ser entregue por nós. Acreditamos que, no momento em que propomos uma alternativa na concepção e no desenvolvimento do conteúdo desta oficina, rompemos algumas barreiras imaginárias na Instituição, pois o foco não mais era a entrega final somente, mas, sim, uma entrega que despertasse efetivamente os docentes para o tema abordado, bem como o envolvimento da equipe neste processo de criação. Isto é, em uma tomada de decisão normal e sadia para todos os envolvidos que resultasse em uma nova cultura digital para a equipe de Tecnologias Educacionais. Sendo assim, estabelecemos as seguintes atividades para os envolvidos diretamente no processo de criação da oficina virtual, ou seja, nossas atividades.

\begin{tabular}{|c|c|c|}
\hline Função & Atividade & Finalidade \\
\hline Designer & $\begin{array}{l}\text { Coletar print de telas das redes sociais. } \\
\text { Construção da linguagem HTML. }\end{array}$ & Inspiração \\
\hline Designer Educacional & $\begin{array}{l}\text { Realizar a análise didática do material entregue pelo } \\
\text { docente. }\end{array}$ & Ideação \\
\hline $\begin{array}{l}\text { Designer e Designer } \\
\text { Educacional }\end{array}$ & $\begin{array}{l}\text { Validar o material entregue junto às equipes que } \\
\text { solicitaram esta demanda. }\end{array}$ & Implementação \\
\hline
\end{tabular}

Tabela 1: Quadro de distribuição das atividades (elaborado pelos autores)

Cabe aqui destacar um fato curioso no que diz respeito à produção de materiais. Geralmente, existe um prazo previamente delimitado para cada atividade, porém, neste caso, solicitamos à coordenação da equipe de Tecnologias Educacionais que fosse destacado somente o prazo final da entrega, deixando assim o tempo de criação livre, dotado de autonomia e responsabilidade por parte dos envolvidos. Neste sentido, buscamos gerar nossas ideias mantendo sempre em mente o seguinte mapa mental desenvolvido por Pinheiro \& Alt (2011) como forma de exemplificar a filosofia do Design Thinking sob a ótica da IDEO, renomada consultoria mundial de inovação. 


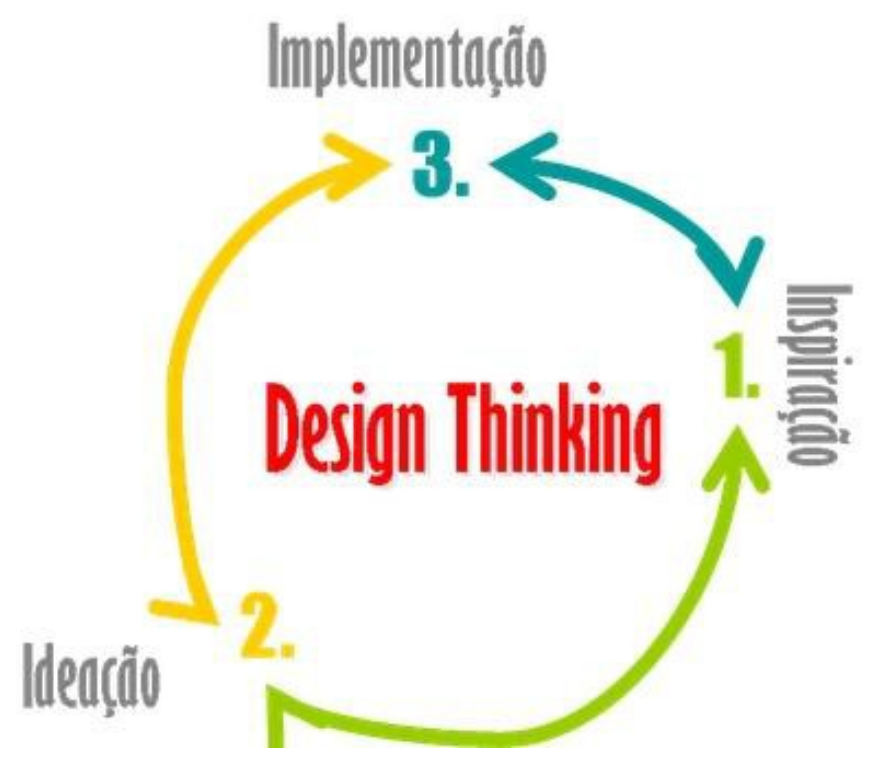

Figura 2: Esquema do Design Thinking na perspectiva da IDEO

(PINHEIRO E ALT, 2011)

Retornando então para a nossa divisão de atividades, enquanto designers coletavam imagens para inspiração, o designer educacional realizava a análise didática para a ideação do material a ser implementado. Do mesmo modo que a coleta de imagens acabou acontecendo com os três envolvidos, a análise didática contou com a participação também dos três profissionais, fato este que julgamos ter sido determinante para a execução bem-sucedida deste projeto. A cocriação foi fundamental para a compreensão do que Brown (2010) denomina continuum da inovação, pois o referido autor acredita que não existe uma forma recomendada ou uma melhor forma para seguir um processo.

Uma equipe ciente da importância de compartilhar ideias e soluções será mais útil do que uma equipe focada diretamente no cumprimento de prazos, preenchimento de planilhas e consequentemente na entrega do produto final o mais breve possível, ressaltando o pensamento de que rapidez é perfeição. Nós buscamos, durante todo o tempo de criação deste projeto, adotar uma postura experimental, em busca de um desafio, de algo motivador.

\footnotetext{
Os design thinkers sabem que não existe uma "melhor forma" de percorrer o processo. Há pontos de partida e pontos de referência úteis ao longo do caminho, mas o continuum da inovação pode ser visto mais como um sistema de espaços que se sobrepõem do que como uma sequência de passos ordenados. Podemos pensar neles como a inspiração, o problema ou a oportunidade que motiva a busca por soluções; a idealização, o processo de gerar, desenvolver e testar ideias; e a implementação, o caminho que vai do estúdio de design ao mercado. Os projetos podem percorrer esses espaços mais de uma vez à medida que a equipe lapida suas ideias e explora novos direcionamentos (BROWN, 2010, p.16).
}

O processo de análise didática então transcorreu dentro da sua normalidade, porém com a equipe devidamente alinhada em suas ideias e pensamentos, mantendo o foco na experiência a ser vivenciada pelos docentes. 


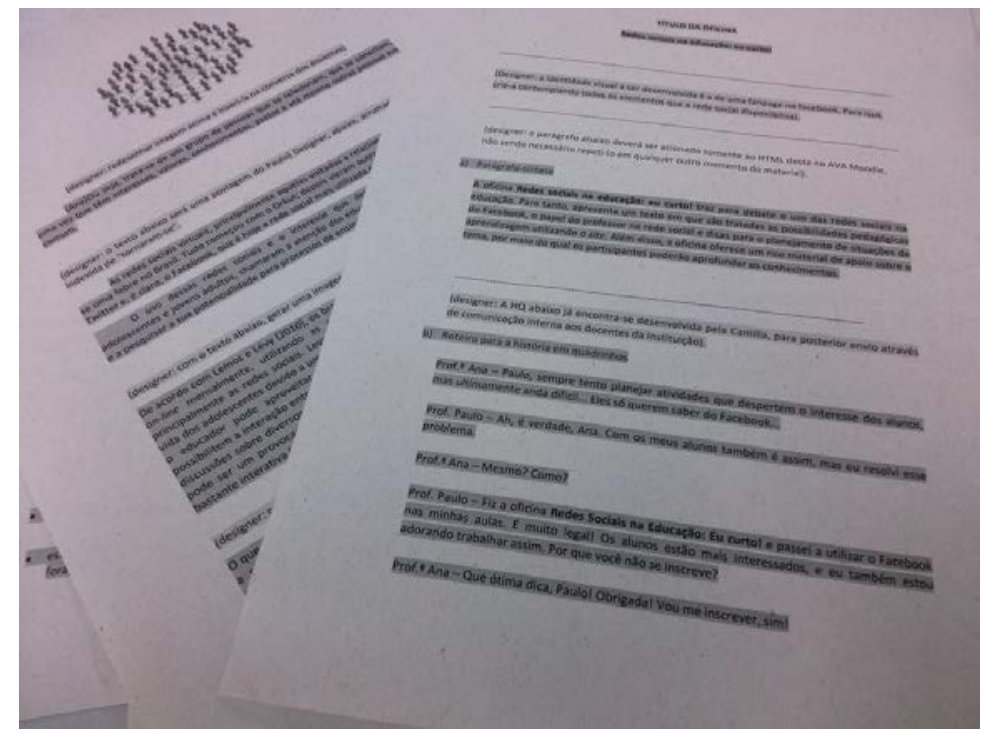

Figura 3: Parte do material após a análise didática (elaborado pelos autores)

Uma vez que o insight havia despertado a criação pedagógica, coube aos envolvidos seguir trabalhando nesta perspectiva cooperativa que Schlemmer diz ser efetivamente criadora no momento em que ocorre a interiorização de regras e os indivíduos realmente colaboram para o desenvolvimento de interesses intrínsecos, onde a equipe controla e estimula ao mesmo tempo a criação. Com a análise didática concluída pelo Designer Educacional, sempre contando com as ideias dos Designers, era hora de esses profissionais traduzirem as ideias descritas que estavam salvas no documento de texto, conforme a imagem abaixo, para a criação visual e linguagem HTML que em breve estaria ao alcance de todos os docentes do Senac RS. A curiosidade que nos mobilizou até aqui certamente nos manteve unidos para finalizar este desafio conforme o resultado nas imagens a seguir.

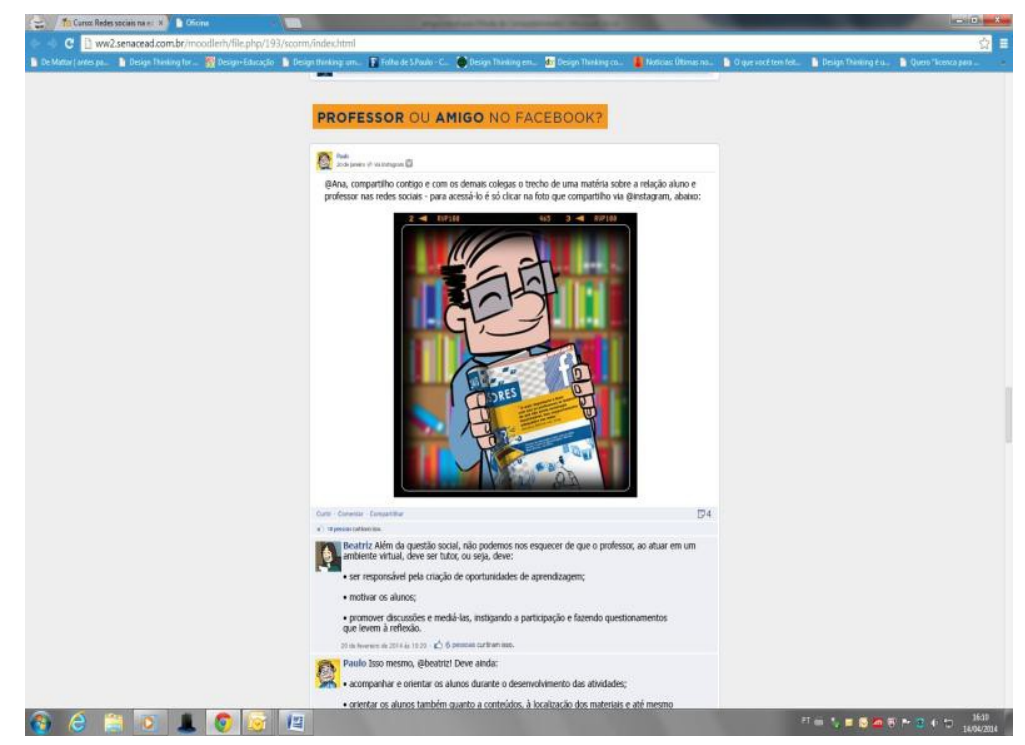

Figura 4: Versão final do material após os momentos de criação (elaborado pelos autores) 
É possível afirmar que nosso trabalho ocorreu como um divertimento normal e sadio, onde nos sentimos parte de um processo que não se encerra por aqui. A oficina ganhou forma, uso de recursos que se assemelhavam à experiência de utilizar a rede social Facebook, entre outras funcionalidades. Isto é, o material outrora entregue em estado bruto, em um documento de texto, nos inspirou a buscar alternativas para idealizar o uso destes pelos docentes, culminando nesta implementação descrita ao longo deste trabalho. Pensar soluções pedagógicas que atendam às necessidades das áreas envolvidas no Senac RS é a nossa missão, sempre por intermédio da empatia, colaboração e experimentação, fundamentais para a criação de soluções inovadoras que façam jus ao nome desta equipe onde estamos inseridos - Tecnologias Educacionais (TED).

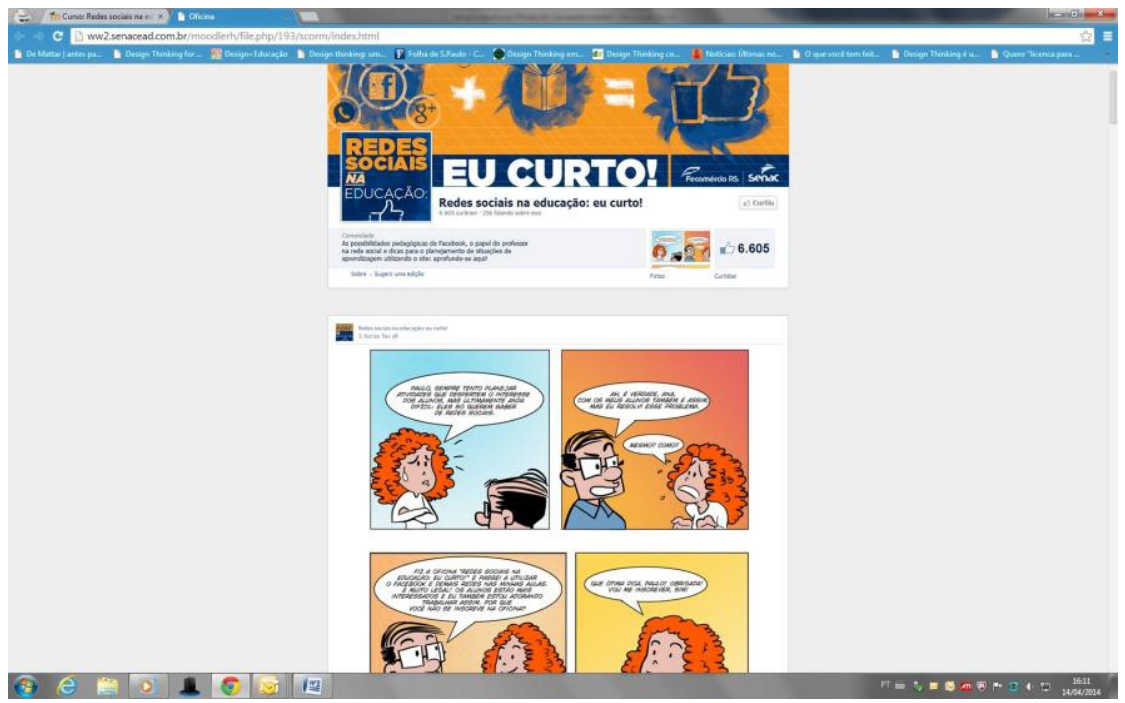

Figura 5: Versão final do material após os momentos de criação (elaborado pelos autores)

\section{Considerações finais}

Nosso trabalho em equipe possibilita o desenvolvimento de diferentes habilidades, de relações sociais, de pensar de maneira diferente. No momento em que trabalhamos em equipe e com o auxílio do Design Thinking como fonte de inspiração para a resolução do nosso problema, trabalhamos com o novo, com o desconhecido, vivenciamos na prática um conceito de Brown (2010) ao destacar que a diferença entre uma equipe entusiástica e uma equipe de entregas convencionais encontra-se no fato de que a entusiástica gera ideias que podem ser em muitos casos revolucionárias, pela sua simplicidade, enquanto uma equipe de entregas convencionais opta pelo caminho das versões enxutas de ideias existentes. Em momento algum estamos condenando uma metodologia em detrimento de outra. O que fizemos, e seguimos fazendo em nossos projetos, é questionar mais, indagar mais, ousar mais.

O cenário interdisciplinar em que nos encontramos inseridos favoreceu muito, inclusive, para o bom andamento da atividade, tornando esta uma fonte de inspiração para novos projetos e solicitações. É importante este tipo de percepção, uma vez que professor e aluno trabalham com pesquisa, com descoberta, e é neste cenário de desbravadores que estamos inseridos a partir de agora. 


\begin{abstract}
Elementos audiovisuais, interativos e sociais aprimoram o conteúdo dos livros e revistas e ferramentas sociais estendem a experiência do leitor para um mundo mais amplo, conectando leitores e permitindo explorações mais profundas e colaborativas do texto. Deixando de ser uma mera reprodução digital de uma obra impressa, as novas interfaces transportam a experiência de leitura com interações táteis a uma nova esfera (MATTAR, 2012, p. 73).
\end{abstract}

Imprescindível para nós é o fato de que nosso momento atual acaba sendo o descrito por Pinheiro \& Alt (2011) ao afirmar a importância de a equipe adquirir um olhar curioso e inovador, como o de uma criança que explora novos brinquedos e novos sentidos, ou seja, que busca inspiração para suas brincadeiras, idealiza como estas deverão acontecer e então as implementa utilizando caixas de papelão para originar sua nave espacial. Nosso embarque não só foi realizado com sucesso como nosso voo foi extremamente tranquilo. Agora estamos prontos para alçar voos ainda maiores e mais longos, com mais desafios.

\title{
Bibliografia
}

BROWN, Tim. Design Thinking: uma metodologia poderosa para decretar o fim das velhas ideias. Rio de Janeiro: Elsevier, 2011.

EUFRASIO JR, Nelson Luis. O Design Thinking como agente inspirador nos processos de criação de materiais educacionais digitais. In: II Congresso IberoAmericano de Estilos de Aprendizagem, Tecnologias e Inovações na Educação - II CIEATIE. Brasília, 2013. Disponível em: http://tinyurl.com/l3vkcxv. Acesso em: 29 jan. 2014.

LOPES, Daniel de Queiroz. Brincando com robôs: desenhando problemas e inventando porquês. Santa Cruz do Sul: EDUNISC, 2010.

LOPES, Daniel de Queiroz e Carla Beatris Valentini. Mídias locativas e realidade mixada: a produção de sentidos sobre o digital-virtual a partir da cartografia com suporte das tecnologias digitais. Revista Educação Unisinos. V. 16, n. 3, 2012, p. 205214. Disponível em: http://tinyurl.com/qjtf63u. Acesso em: 17 jun. 2013.

MATTAR, João. Tutoria e interação em educação a distância. São Paulo: Cengage Learning, 2012.

PINHEIRO, Tennyson. ALT, Luis. Design Thinking Brasil: empatia, colaboração e experimentação para as pessoas, negócios e sociedade. Rio de Janeiro: Elsevier, 2011.

SCHLEMMER, Eliane. Colaboração e cooperação na educação online: da formação à ação pedagógica em rede utilizando a tecnologia de Metaverso. In: DAMIANI, Magda Floriana. PORTO, Tânia Maria Esperón. SCHLEMMER, Eliane. (Orgs.) Trabalho colaborativo/cooperativo em educação: uma possibilidade para ensinar e aprender. São Leopoldo: Oikos; Brasília: Liber Livro, 2009. 